\title{
Iron absorption during normal human pregnancy: a study using stable isotopes
}

\author{
BY PAUL G. WHITTAKER AND TOM LIND \\ University Department of Obstetrics and Gynaecology. Princess Mary Maternity Hospital, \\ Newcastle, Tyne and Wear NE2 3BD \\ AND JOHN G. WILLIAMS \\ NERC ICP-MS Facility, Department of Geology, Royal Holloway and Bedford New College, \\ Egham, Surrey TW20 OEX
}

(Received 15 May 1990 - Accepted 9 October 1990)

\begin{abstract}
The absorption of iron has been determined in nine healthy women studied serially during pregnancy and once post delivery. Following the oral administration of $5 \mathrm{mg}$ aqueous ${ }^{54} \mathrm{FeSO}_{4}$ plus ascorbic acid and the intravenous injection of $200 \mu \mathrm{g}{ }^{57} \mathrm{FeSO}$, the isotope ratios of ${ }^{54} \mathrm{Fe}:{ }^{56} \mathrm{Fe}$ and ${ }^{57} \mathrm{Fe}:{ }^{56} \mathrm{Fe}$ in serum were measured by the use of inductively-coupled-plasma mass spectrometry whereby metal ions are vaporized into an argon plasma without previous blood sample preparation. Mean oral Fe absorption was 7.6 (range 1-22) \% at 12 weeks gestation, $21 \cdot 1$ (range 9-58) \% at 24 weeks, 37.4 (range 18-56) \% at 36 weeks and 26.3 (range 8-54) \% at 12 weeks post delivery. All the other biochemical and haematological indices were within normal limits for pregnancy. The significant increase $(P<0.01)$ in Fe absorption during normal pregnancy suggests that most women would have the potential to meet the Fe demands of pregnancy without the need for supplementation if dietary Fe has similar availability to the aqueous preparation.
\end{abstract}

Iron absorption: Human pregnancy: Stable isotopes

Despite the widespread practice of prescribing iron supplements during pregnancy, findings showing that the additional Fe requirements of pregnancy cannot be met from the daily diet of mothers living in the western world are conflicting. A Swedish study found daily intake to be $9833 \mathrm{~kJ}(2350 \mathrm{kcal})$ and $17 \mathrm{mg}$ Fe during pregnancy (Svanberg et al. $1975 \mathrm{~b}$ ), i.e. $7.2 \mathrm{mg} / 4184 \mathrm{~kJ}(1000 \mathrm{kcal})$, while American findings suggest that on average diets will contain about $6 \mathrm{mg} \mathrm{Fe} / 4184 \mathrm{~kJ}$ (1000 kcal) (Bothwell et al. $1979 \mathrm{a})$. A recent dietary study showed English women to consume daily about $7950 \mathrm{~kJ}(1900 \mathrm{kcal})$ and $10.5 \mathrm{mg} \mathrm{Fe}$ when not pregnant ( $13 \%$ below English recommended daily allowance), compared with $9205 \mathrm{~kJ}$ (2200 kcal) and $12.5 \mathrm{mg}$ during pregnancy (Schofield et al. 1987, 1989). If the daily loss from cell desquamation, hair loss and menstrual bleeding averages about $2 \mathrm{mg} / \mathrm{d}$ then absorption has to be about $16 \%$ (of the recommended daily allowance) in non-pregnant women. The estimates of how much extra $\mathrm{Fe}$ is needed during normal pregnancy vary widely ranging from 0 to about $1400 \mathrm{mg}$ in total (Lind, 1983) and also depend on $\mathrm{Fe}$ reserve. It has been suggested that Fe requirements are $1 \mathrm{mg} / \mathrm{d}$ in the first trimester, $4 \mathrm{mg} / \mathrm{d}$ in the second trimester and about $6 \mathrm{mg} / \mathrm{d}$ in the third trimester (Bothwell et al. 1979a). Fe absorption would have to increase to about $48 \%$ in late pregnancy. While there is general agreement that $\mathrm{Fe}$ absorption does increase during pregnancy, reports concerning the amount of any increase vary from 40 to $90 \%$ (Hahn et al. 1951; Heinrich 1970; Svandberg et al. 1975 a). These studies employed radioactive isotopes as tracers of Fe. We report a serial study of $\mathrm{Fe}$ absorption during pregnancy using stable isotopes and a specially 
developed measuring technique using inductively-coupled-plasma mass spectrometry (ICP-MS; Whittaker et al. 1989).

\section{MATERIALS AND METHODS}

\section{Chemicals}

${ }^{54} \mathrm{Fe}$ and ${ }^{57} \mathrm{Fe}$ enriched to $95 \%$ were obtained as ferrous sulphate from the UK Atomic Energy Authority at Harwell. Both forms of $\mathrm{FeSO}_{4}$ were dissolved in double-distilled deionized water with $3 \mathrm{mg}$ ascorbic acid/ml (final $\mathrm{pH} 2.9$ ) and $5 \mathrm{ml}$ portions of the solutions prepared to pharmacological standard were sealed under nitrogen in glass ampoules. Oxidation of ferrous $\mathrm{Fe}$ was estimated at $10 \%$ over 6 months. Those ampoules for oral administration contained $5.23 \mathrm{mg}$ total $\mathrm{Fe}$, equivalent to $5.01 \mathrm{mg}{ }^{54} \mathrm{Fe}$, and those for intravenous administration contained $196 \mu \mathrm{g}$ total $\mathrm{Fe}, 187 \mu \mathrm{g}$ as ${ }^{57} \mathrm{Fe}$.

\section{Patients}

Nine normal healthy women were studied serially at 12,24 and 36 weeks of pregnancy and again at 12 weeks after delivery. Tests undertaken at each visit to assess Fe status included serum $\mathrm{Fe}$, ferritin, transferrin, vitamin $\mathrm{B}_{12}$, folate, haemoglobin, erythrocyte count and mean cell volume (MCV). The women were in good general health, were non-smokers and did not take $\mathrm{Fe}$ supplements before or during pregnancy. Ethical approval had been obtained from the Ethics Committee of Newcastle District Health Authority.

\section{Patient protocol}

Subjects were fasted overnight for at least $10 \mathrm{~h}$. After sitting at rest in a warm room, a $20 \mathrm{ml}$ basal venous blood sample was taken then $187 \mu \mathrm{g}{ }^{57} \mathrm{Fe}$ was given intravenously; 5 min later $5 \mathrm{mg}{ }^{54} \mathrm{Fe}$ was given by mouth in $60 \mathrm{ml}$ water. Further $5 \mathrm{ml}$ blood samples were taken every 30 min over $6 \mathrm{~h}$ and the serum was stored at $-20^{\circ}$ until assayed.

During pregnancy women often experience feelings of nausea and sometimes actual vomiting, especially in the morning. This is often made worse by prolonged fasting particularly during early pregnancy. To achieve as comparable a basal state as possible, both between patients and within patients between occasions, $30 \mathrm{~min}$ after the oral load of Fe a light breakfast of a cup of tea or coffee plus two slices of thin white toast was offered. This minimal fixed meal satisfied the feelings of hunger while keeping the effect of food intake for each patient as consistent as possible across test occasions. While the patients were, therefore, not maintained in a pure fasted state we believe it was necessary for the comfort of the patient and maintained a reasonably constant effect physiologically. Lunch was taken after $3 \mathrm{~h}$.

\section{Isotope analysis}

Detailed descriptions of the ICP-MS method, including a modification of the sample introduction technique to reduce significantly the levels of certain polyatomic ion interferences, have already been published (Whittaker et al. 1989). In brief, $5 \mu 1$ serum is placed onto a graphite rod in a furnance attached to an ICP-MS. A 1 min electrothermal cycle is initiated, involving drying, to 'drive off' the water content of the sample, and ashing, whereby organic material is burnt off. Finally, high temperature vaporization for $5 \mathrm{~s}$ drives off the remaining material containing the elements of interest into the argon plasma for ionization before introduction into the mass spectrometer. Collecting the results takes $10 \mathrm{~s}$ and there are four runs per sample, plus a blank run. The total time to complete a single sample analysis is approximately $15 \mathrm{~min}$.

Isotope ratio accuracy was assessed with aqueous solutions of natural $\mathrm{Fe}(1 \mu \mathrm{g} / \mathrm{ml})$ and 
solutions of known enrichment from Harwell. On each day of analysis, natural ratios were checked with a quality control basal serum sample together with one from each patient, to enable assessment of background interference and across assay variability to be determined.

Assay reproducibility was averaged over ten assays. The coefficient of variation for the ${ }^{54} \mathrm{Fe}:{ }^{56} \mathrm{Fe}$ isotope ratio was $2.6 \%$ within samples and $4.7 \%$ across assays. Corresponding values for ${ }^{57} \mathrm{Fe}:{ }^{56} \mathrm{Fe}$ were 3.5 and $4.6 \%$. The limit of detection of enrichment (3 SD above basal) was a ratio of 0.0060 for ${ }^{54} \mathrm{Fe}:{ }^{56} \mathrm{Fe}$ and 0.0033 for ${ }^{57} \mathrm{Fe}:{ }^{56} \mathrm{Fe}$.

\section{Pharmacokinetic analysis}

Estimation of absorption after oral administration of drugs is most commonly determined by comparison of the total area under the curves (AUC) plotted for drug concentration $v$. time following oral and intravenous administration (Gibaldi \& Perrier, 1982). This has been applied to a wide range of drugs and seemed appropriate for our stable isotopes of $\mathrm{Fe}$ using enrichment in $\mathrm{Fe}$ isotope ratio rather than concentration. AUC is most easily calculated by the trapezoidal rule, hence the more sample occasions the better the estimate. Because blood sampling is usually discontinued before the tracer-enrichment values in plasma have returned to the basal value an extrapolation area is calculated from the enrichment at the last sample time and an estimate of the elimination rate constant. The smaller the contribution of the extrapolation area to the total area, the more accurate the estimation of total area. In the present study, for example, the $6 \mathrm{~h}$ AUC, as a percentage of the total estimated AUC, averaged 77 (SD 7 ) for the oral tracer and 85 (SD 8) for the intravenous tracer (in late pregnancy); such values are considered adequate for pharmacological studies. The advantage gained by using stable isotopes was that the oral ${ }^{54} \mathrm{Fe}:{ }^{56} \mathrm{Fe}$ AUC(oral) and the intravenous ${ }^{57} \mathrm{Fe}:{ }^{56} \mathrm{Fe}$ AUC(iv) could be estimated simultaneously. The ratio of these areas after intravenous and oral administration of equal doses would be equivalent to the fraction absorbed. When different doses are given as in the present study, then

$$
\text { oral absorption }=\frac{\mathrm{AUC}(\text { oral })}{\mathrm{AUC}(\mathrm{iv})} \times \frac{\operatorname{dose}(\mathrm{iv})}{\operatorname{dose}(\text { oral })} .
$$

\section{Statistical analysis}

Variability was expressed as the standard deviation of the mean and values were analysed using two-way analysis of variance followed by the paired $t$ test (two-sided).

\section{RESULTS}

Isotope enrichment in serum

Fig. 1 shows the time course of enrichment of the two Fe isotopes in one subject during late pregnancy. ${ }^{57} \mathrm{Fe}(187 \mu \mathrm{g})$ given intravenously increased the natural ${ }^{57} \mathrm{Fe}:{ }^{56} \mathrm{Fe}$ ratio from 0.03 to 0.075 by $15 \mathrm{~min}$, decreasing thereafter such that the $6 \mathrm{~h}$ sample was close to the limits of detection. Oral absorption of the ${ }^{54} \mathrm{Fe}$ isotope gave a peak in the ${ }^{54} \mathrm{Fe}:{ }^{56} \mathrm{Fe}$ ratio $45 \mathrm{~min}$ after ingestion. This particular subject displayed high Fe absorption (45\%). The decline in the ${ }^{54} \mathrm{Fe}:{ }^{56} \mathrm{Fe}$ ratio was analysed in all nine subjects and between 150 and $360 \mathrm{~min}$ the mean half-time was 161 (SD 47) min during the first trimester; it was unchanged during the second trimester but decreased to 105 (SD 17) min during the third trimester. This change was significant $(P<0 \cdot 01)$. The decline in the ${ }^{57} \mathrm{Fe}:{ }^{56} \mathrm{Fe}$ ratio between 30 and $360 \mathrm{~min}$ was also calculated; during the first trimester it equalled 104 (SD 17) min and during the third trimester it was 88 (SD 22) min $(P<0.05)$. Half-times at 12 weeks post delivery were similar to those in early pregnancy. 


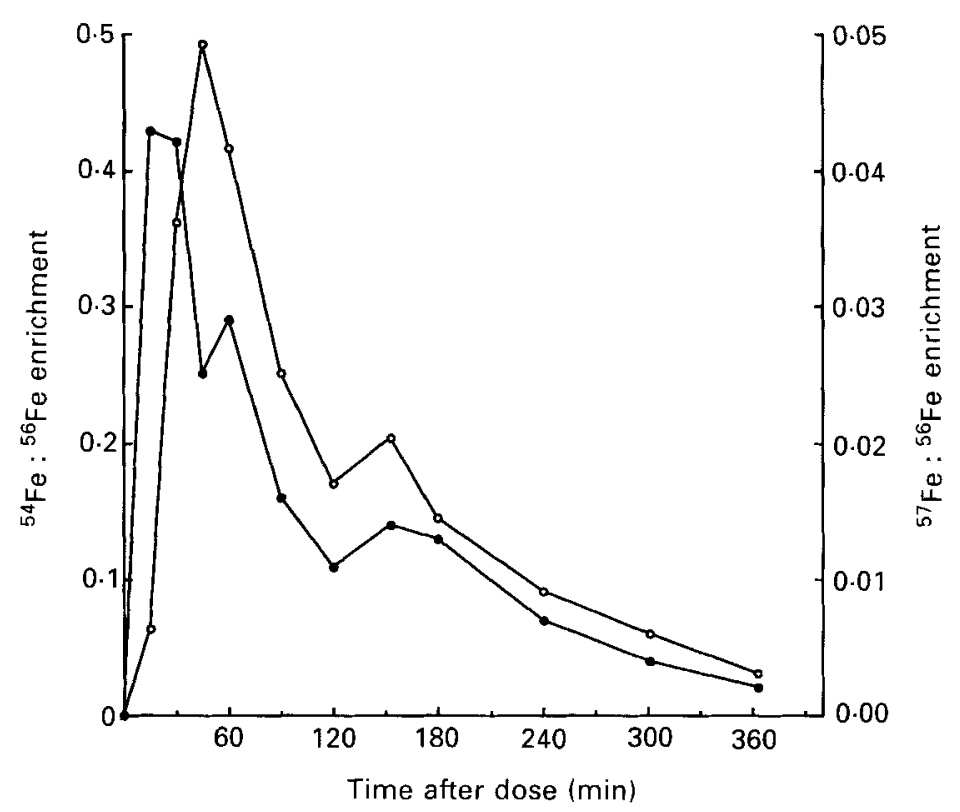

Fig. 1. Changes in serum iron isotope ratio enrichment following the administration of $5 \mathrm{mg}{ }^{54} \mathrm{Fe}$ orally and $187 \mu \mathrm{g}{ }^{57} \mathrm{Fe}$ intravenously, to a subject during late pregnancy. For details of procedures, see p. 458. (O), ${ }^{54} \mathrm{Fe}:{ }^{56} \mathrm{Fe} ;()^{57} \mathrm{Fe}:{ }^{58} \mathrm{Fe}$.

Table 1. Oral absorption (\%) of $5 \mathrm{mg}$ ferrous sulphate during normal pregnancy in healthy subjects $\dagger$

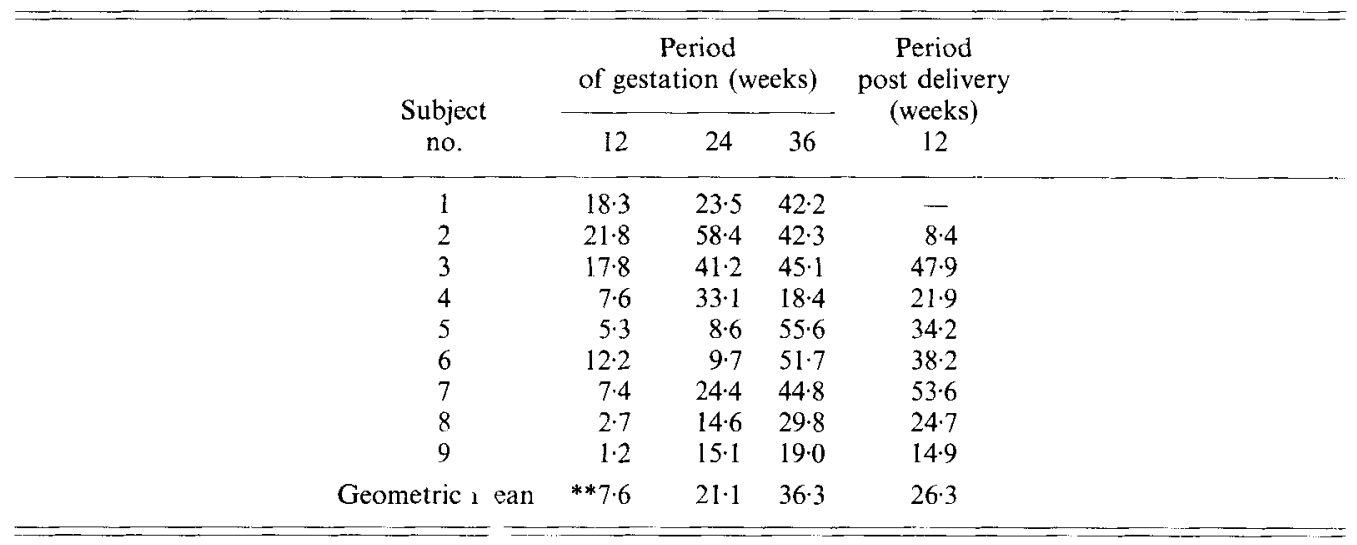

Mean value was lower than $\mathrm{tL}$ se of later gestational groups (paired $t$ test): ${ }^{* *} P<0 \cdot 01$.

$\dagger$ For details of procedures, see '. 458.

\section{Fe absorption}

The percentage of the oral $5 \mathrm{mg}$ dose of $\mathrm{FeSO}_{4}$ absorbed is shown in Table 1. At 12 weeks gestation there was a wide range of values, but within the range expected for non-pregnant subjects. By 24 weeks absorption had increased in eight of the nine subjects and by 36 weeks absorption had increased further in seven of the nine subjects. By 12 weeks post delivery, absorption had decreased in five of eight women but was still much higher than the first trimester value in seven out of the nine women. 
Table 2. Haematological indices during normal pregnancy in healthy subjects $\dagger$

(Mean values and standard deviations)

\begin{tabular}{|c|c|c|c|c|c|c|c|c|}
\hline & \multicolumn{6}{|c|}{ Period of gestation (weeks) } & \multirow{2}{*}{\multicolumn{2}{|c|}{$\begin{array}{c}\begin{array}{c}\text { Period post } \\
\text { delivery (weeks) }\end{array} \\
\frac{12}{12}\end{array}$}} \\
\hline & \multicolumn{2}{|c|}{12} & \multicolumn{2}{|c|}{24} & \multicolumn{2}{|l|}{36} & & \\
\hline & Mean & SD & Mean & $\mathrm{SD}$ & Mean & $\mathrm{SD}$ & Mean & $\mathrm{SD}$ \\
\hline Haemoglobin $(\mathrm{g} / \mathrm{l})$ & 124 & 5 & $* 116$ & 6 & $* * 110$ & 6 & $* * * 128$ & 7 \\
\hline $\operatorname{MCV}(f)$ & $91 \cdot 9$ & $2 \cdot 1$ & $* 93 \cdot 4$ & $2 \cdot 7$ & $* * 89 \cdot 1$ & $4: 1$ & $* * * 85.7$ & $3 \cdot 2$ \\
\hline Ferritin $(\mu \mathrm{g} / \mathrm{l})$ & 34 & 20 & $* 15$ & 9 & $* 7$ & 3 & $* 20$ & 14 \\
\hline Serum iron $(\mu \mathrm{mol} / 1)$ & 19 & 4 & 15 & 4 & $* * 8$ & 2 & $* * * 18$ & 5 \\
\hline Transferrin saturation $(\%)$ & 26 & 7 & 16 & 7 & $* * 7$ & 2 & $* * * 23$ & 7 \\
\hline
\end{tabular}

MCV, mean cell volume.

Mean value was significantly different from preceding value: ${ }^{*} P<0.05,{ }^{* *} P<0.01,{ }^{* * *} P<0.001$ (paired $t$ test).

$\uparrow$ For details of procedures, see p. 458.

\section{Haematological indices}

Changes in haemoglobin, MCV, serum ferritin, serum Fe and transferrin saturation during pregnancy are presented in Table 2. At 12 weeks gestation, the haemoglobin concentration was above $115 \mathrm{~g} / \mathrm{l}$ in all subjects and the serum ferritin values were in the range $10-77 \mu \mathrm{g} / 1$. There was no correlation between ferritin or haemoglobin concentrations and $\mathrm{Fe}$ absorption. At 36 weeks gestation, the low haemoglobin and serum ferritin values that occurred in some mothers, together with the decrease in transferrin saturation, might be regarded as evidence of $\mathrm{Fe}$ insufficiency, but none of these changes correlated with $\mathrm{Fe}$ absorption. Despite the fact that Fe was not prescribed post delivery, all haematological indices had returned to the normal range by 12 weeks.

\section{DISCUSSION}

The natural abundances $(\%)$ of the stable isotopes of $\mathrm{Fe}$ are ${ }^{54} \mathrm{Fe} 5 \cdot 8,{ }^{56} \mathrm{Fe} 91 \cdot 7,{ }^{57} \mathrm{Fe} 2 \cdot 2$, ${ }^{58} \mathrm{Fe} 0 \cdot 3$. As $\mathrm{Fe}$ is not a volatile element, previous efforts to determine $\mathrm{Fe}$ absorption using stable isotopes by neutron activation or thermal ionization mass spectrometry involved complex and time-consuming sample preparation before measurement (Dyer \& Brill, 1972; King et al. 1978; Miller \& Van Campen, 1979; Johnson, 1982). The use of ICP-MS has considerable advantages.

A variety of protocols have been tried over the years to assess $\mathrm{Fe}$ absorption, the accepted reference method being the use of radioactive ferrous salts (plus ascorbic acid) with measurement by whole-body counting about 10-20 d after the test (Bothwell et al. $1979 \mathrm{~b}$ ). This technique is limited to radioactive tracers. Incorporation of tracer Fe into erythrocytes, measured 2 weeks after tracer administration, has been shown to have a close correlation with whole-body counting when both oral and intravenous tracers are used (Werner et al. 1983). With stable isotopes this presents problems of measuring enrichment of the whole-body Fe pool with two isotopes at physiological doses. However, the use of a single ingested isotope, ${ }^{58} \mathrm{Fe}$ (Janghorbani et al. 1986) and subsequent measurement of erythrocyte incorporation is unfortunately only semi-quantitative, since Fe incorporation into erythrocytes alters from $95 \%$ in non-pregnant subjects (Larsen \& Milman, 1975) to $65 \%$ in subjects during late pregnancy (Dyer \& Brill, 1972). This present study has 
therefore chosen to use a double isotope approach $\left({ }^{54} \mathrm{Fe}\right.$ and $\left.{ }^{57} \mathrm{Fe}\right)$ to assess $\mathrm{Fe}$ absorption from the short-term post-absorption plasma levels. Although this method has been claimed not to be sufficiently precise (Bothwell et al. 1955), Werner et al. (1983) showed a correlation of 0.99 between absorption calculated from double isotope plasma activity over $4 \mathrm{~h}$ and absorption calculated from whole-body counting.

Using a whole-body counter, Svanberg et al. (1975a) (with $3 \mathrm{mg} \mathrm{Fe}$ ) found mean oral absorption to be 35 (range 16-45) \% in eight normal non-pregnant women; in contrast, Heinrich (1970) (with $5 \mathrm{mg} \mathrm{Fe}$ ) reported mean absorption as 14 (SD 6) \% in thirty-three normal female subjects. Our estimate (using $5 \mathrm{mg}$ Fe in $6 \mathrm{~h}$ studies) was 10 (range $8-17$ ) \% (Whittaker et al. 1989). It could be argued that the breakfast we gave had some inhibitory effect, being closer to the time of Fe administration than the other two studies in which food was given $2 \mathrm{~h}$ later. However, at 12 weeks gestation we found oral absorption to have a median value of $8 \%$, little changed from our non-pregnant values. Svanberg (1975) estimated it to be a median of $12 \%$, considerably lower than their non-pregnant level, but close to our estimate for early gestation, and very similar to the $11 \%$ result of Hahn et al. (1951), who used 2-9 $\mathrm{mg}{ }^{59} \mathrm{Fe}$ salt and estimated oral absorption from erythrocyte incorporation. Our mean values for later gestation, of 21 and $37 \%$ at 24 and 36 weeks respectively, contrast with the estimate of Heinrich (1970) of $42 \%$ at 16 weeks, $75 \%$ at 24 weeks and $90 \%$ at 38 weeks. However their iron dose was considerably less than ours, which may have facilitated greater absorption. Hahn et al. (1951) found $17 \%$ absorption at 16 weeks, $32 \%$ at 24 weeks and $41 \%$ after 35 weeks. Despite the differences in the actual values, the findings nevertheless suggest that a major increase in $\mathrm{Fe}$ absorption occurs before 24 weeks of gestation. Dyer \& Brill (1972), using $5 \mathrm{mg}{ }^{58} \mathrm{Fe}$ salt and estimating oral absorption from the subsequent erythrocyte incorporation, found a mean absorption of $50 \%$ between 23 and 38 weeks of pregnancy, but without any apparent trend during gestation. Our value of an average of $26 \%$ absorption 12 weeks after a normal delivery is not directly comparable with the estimate of Svanberg (1975) of $43 \%$ which was determined at 9 weeks after deliberate termination of early pregnancies. There is agreement, however, that post-delivery values are above those at 12 weeks gestation.

There thus appears to be considerable variation in the amount of oral inorganic $\mathrm{Fe}$ apparently absorbed during pregnancy; in some measure the differences relate both to the different methods employed and to the considerable variation found both betweenindividuals within-occasions as well as within-patients between-occasions. Of the studies mentioned, ours is the only serial investigation using aqueous inorganic Fe during pregnancy; that of Svanberg et al. (1975a) used radioactive tracer Fe added to food (only reference dose values have been given previously). Their chosen composite meal had only $10 \%$ of the $\mathrm{Fe}$ bioavailability of their aqueous reference dose but their meat meal (not tested serially) was said to have $25 \%$ of the bioavailability of their reference dose. While it is clear that $\mathrm{Fe}$ absorption from an aqueous solution increases markedly during pregnancy, absorption of Fe from the everyday diet will be influenced by both 'good' and 'poor' bioavailability. Seven of our nine subjects had absorption values over $30 \%$ during the third trimester of pregnancy, suggesting that absorption can increase sufficiently to meet the Fe requirement of pregnancy if present-day diets contain this mineral in a bioavailable form. Further stable isotope studies are now under way to assess this.

Financial support was received from Birthright and the MoD. We gratefully acknowledge the help of Sister J. Gerrard (SRN, SCM), Newcastle, and Dr Alan Gray, Surrey. The ICPMS unit is an NERC analytical facility. 


\section{REFERENCES}

Bothwell, T. H., Charlton, R. W., Cook, J. D. \& Finch, C. A. (1979 a). Iron nutrition. In Iron Metabolism in Man, pp. 7-42. London: Blackwell.

Bothwell, T. H., Charlton, R. W., Cook, J. D. \& Finch, C. A. (1979 b). Measurement of iron absorption. In Iron Metabolism in Man, pp. 425 438. London: Blackwell.

Bothwell, T. H., Mallett, B., Oliver, R. \& Smith, M. D. (1955). The inability to assess the absorption of iron from plasma radioiron curves. British Journal of Haematology 1, 352-357.

Dyer, N. C. \& Brill, A. B. (1972). Use of the stable tracers ${ }^{58} \mathrm{Fe}$ and ${ }^{50} \mathrm{Cr}$ for the study of iron utilization in pregnant women. Nuclear Activation Techniques in the Life Sciences, pp. 469-477. Vienna: IAEA.

Gibaldi, M. \& Perrier, D. (1982). Absorption kinetics and bioavailability. Pharmacokinetics, pp. 145-198. New York: Marcel Dekker.

Hahn, P. F., Carothers, E. L., Darby, W. J., Martin, M., Sheppard, C. W., Cannon, R. O., Beam, A. S., Densen, P. M., Peterson, J. C. \& McClellan, G. S. (1951). Iron metabolism in early pregnancy as studied with the radioactive isotope ${ }^{59} \mathrm{Fe}$. American Journal of Obstetrics and Gynecology 61, 477-486.

Heinrich, H. C. (1970). Intestinal iron absorption in man. In Iron Deficiency, pp. 213-296 [L. Hallberg, H.-G. Harwerth and $\mathrm{A}$. Vannotti, editors]. London: Academic Press.

Janghorbani, M., Ting, B. T. G. \& Fomon, S. J. (1986). Erythrocyte incorporation of ingested stable isotope of iron $\left({ }^{58} \mathrm{Fe}\right)$. American Journal of Hematology 21, 277-288.

Johnson, P. E. (1982). A mass spectrometric method for use of stable isotopes as tracers in studies of iron, zine and copper absorption in human subjects. Journal of Nutrition 112, 1414-1424.

King, J. C., Raynolds, W. L. \& Margen, S. (1978). Absorption of stable isotopes of iron, copper and zinc during oral contraceptive use. American Journal of Clinical Nutrition 31, 1198-1203.

Larsen, L. \& Milman, N. (1975). Normal iron absorption determined by means of whole body counting and red cell incorporation of ${ }^{59} \mathrm{Fe}$. Acta Medica Scandinavica 198, 271-274.

Lind, T. (1983). Iron supplementation during pregnancy. In Nutrition in Pregnancy, pp. 181-192 [D. M. Campbell and R. D. G. Gilmer, editors]. London: Royal College of Obstetricians and Gynaecologists.

Miller, D. D. \& Van Campen D. (1979). A method for the detection and assay of iron stable isotopes in blood serum. American Journal of Clinical Nutrition 32, 2354-2361.

Schofield, C., Stewart, J. \& Wheeler, E. (1987). The diets of pregnant and post-pregnant women in different social groups in London and Edinburgh: energy, protein, fat and fibre. British Journal of Nutrition 58, 369-381.

Schofield, C., Stewart, J. \& Wheeler, E. (1989). The diets of pregnant and post-pregnant women in different social groups in London and Edinburgh: calcium, iron, retinol, ascorbic acid and folic acid. British Journal of Nutrition 62, 363-377.

Svanberg, B. (1975). Iron absorption in early pregnancy - a study of the absorption of non-haem iron and ferrous iron in early pregnancy. Acta Obstetricia Gynecologia Scandinavica 48, Suppl. 69-86.

Svanberg, B., Arvidsson, B., Bjorn-Rasmussen, E., Hallberg, L., Rossander, L. \& Swolin B. (1975a). Dietary iron absorption in pregnancy - a longitudinal study with repeated measurements of non-haem iron absorption from whole diet. Acta Obstetricia Gynecologica Scandinavica 48, Suppl. 43-68.

Svanberg, B., Rossander, L. \& Isaksson, B. (1975 b). Studies of dietary habits in pregnancy - with special reference to the intake of iron. Acta Obstetricia Gynecologica Scandinavica 48, Suppl. 29-42.

Werner, E., Hansen, C., Roth, P. \& Kaltwasser, J. P. (1983). Comparative evaluation of intestinal iron absorption by four different methods in man. In Structure and Function of Iron Storage and Transport Proteins, pp. 403-408 [I. Urushizaki, P. Aisen, 1. Listowsky and J. W. Drysdale, editors]. Oxford: Elsevier Science.

Whittaker, P. G., Lind, T., Williams, J. G. \& Gray, A. L. (1989). Inductively coupled plasma mass spectrometric determination of the absorption of iron in normal women. Analyst 114, 675-678. 